\title{
Automated segmentation of routine cine-CMR for volumetric assessment of presence and severity of left ventricular diastolic dysfunction
}

\author{
Dorinna D Mendoza*, Noel CF Codella, Sonia Sethi, Keigo Kawaji, \\ Shant Manoushagian, Martin R Prince, Richard B Devereux, James K Min, \\ Matthew D Cham, Yi Wang and Jonathan W Weinsaft
}

Address: Weill Cornell Medical College, New York, NY, USA

* Corresponding author

from 13th Annual SCMR Scientific Sessions

Phoenix, AZ, USA. 2I-24 January 2010

Published: 21 January 2010

Journal of Cardiovascular Magnetic Resonance 2010, I2(Suppl I):P86 doi:10.I 186/I532-429X-I2-SI-P86

This abstract is available from: http://jcmr-online.com/content/I2/SI/P86

(c) 2010 Mendoza et al; licensee BioMed Central Ltd.

\section{Objective}

To compare automated volumetric segmentation of routine cine-CMR to echocardiography (echo) for assessment of $\mathrm{LV}$ diastolic function.

\section{Introduction}

DD alters LV relaxation and compliance, thereby changing timing profiles of LV filling. Cine-CMR provides volumetric data concerning LV filling but is not widely used to assess DD as manual planimetry of all images across all temporal phases requires tracing over one hundred images per exam. Thus, whereas cine-CMR is a reference for systolic function, additional testing using echo is typically necessary to identify DD. We tested whether automated segmentation of routine cine-CMR could be used to stratify presence and severity of DD.

\section{Methods}

The population consisted of consecutive post-myocardial infarction patients who prospectively underwent CMR (1.5 T, SSFP) and echo within 1 day. CMR and echo were independently interpreted. Echo was the reference for DD (graded using American Society of Echocardiography criteria). Cine-CMR assessed LV filling using our group's previously validated automated segmentation algorithm (LVMETRIC) - volumetric segmentation of all LV short-axis slices across all temporal phases generated a volumetric- filling profile. Three parameters were tested: Peak Filling Rate (PFR) - maximal Ävolume/Äphase. Time to Peak Filling Rate (TPFR) - interval between end-systole and peak filling. Diastolic Volume Recovery (DVR) - proportion of diastole required to recover a given percent $(80 \%)$ stroke volume.

\section{Results}

113 patients were studied ( $57 \pm 13$ years, $43 \%$ HTN, LVEF $=54 \pm 13 \%) .64 \%$ had echo-evidenced DD ( $25 \%$ grade 1 , $63 \%$ grade $2,12 \%$ grade 3 ). LV-METRIC successfully generated LV filling curves $(190 \pm 36$ images/exam) in $99 \%$ patients $(1=$ arrhythmia $)$. Patients with DD had longer DVR $(73 \pm 13$ vs. $66 \pm 16 \%, p=0.01)$, longer TPFR (239 \pm 164 vs. $177 \pm 123 \mathrm{msec}, \mathrm{p}=0.03)$, and a trend towards lower PFR ( $234 \pm 83$ vs. $265 \pm 77 \mathrm{ml} / \mathrm{sec}, \mathrm{p}=0.07)$ vs. those without DD by echo. TPFR by cine-CMR correlated with echo deceleration time by echo $(\mathrm{r}=0.25, \mathrm{p}=0.02)$. In multivariate analysis, echo-evidenced DD was independently associated with DVR (OR 1.36 per 10 point increment $[\mathrm{CI}=1.04-1.69] \mathrm{p}=0.03)$ after controlling for LVEF (OR 1.48 per 10 point decrement [1.02-1.95] $\mathrm{p}=$ 0.04 ), and HTN (OR 3.07 [1.21-7.83], $\mathrm{p}=0.02$ ) [model $\left.\chi^{2}=16.3 ; \mathrm{p}=0.001\right]$. CMR filling parameters also stratified severity of DD, as evidenced by a stepwise DVR decrease (Figure 1A) and PFR increase (1B) from grade 1 to grade 3 echo-assigned DD grade (both $\mathrm{p}<0.001$ ). 

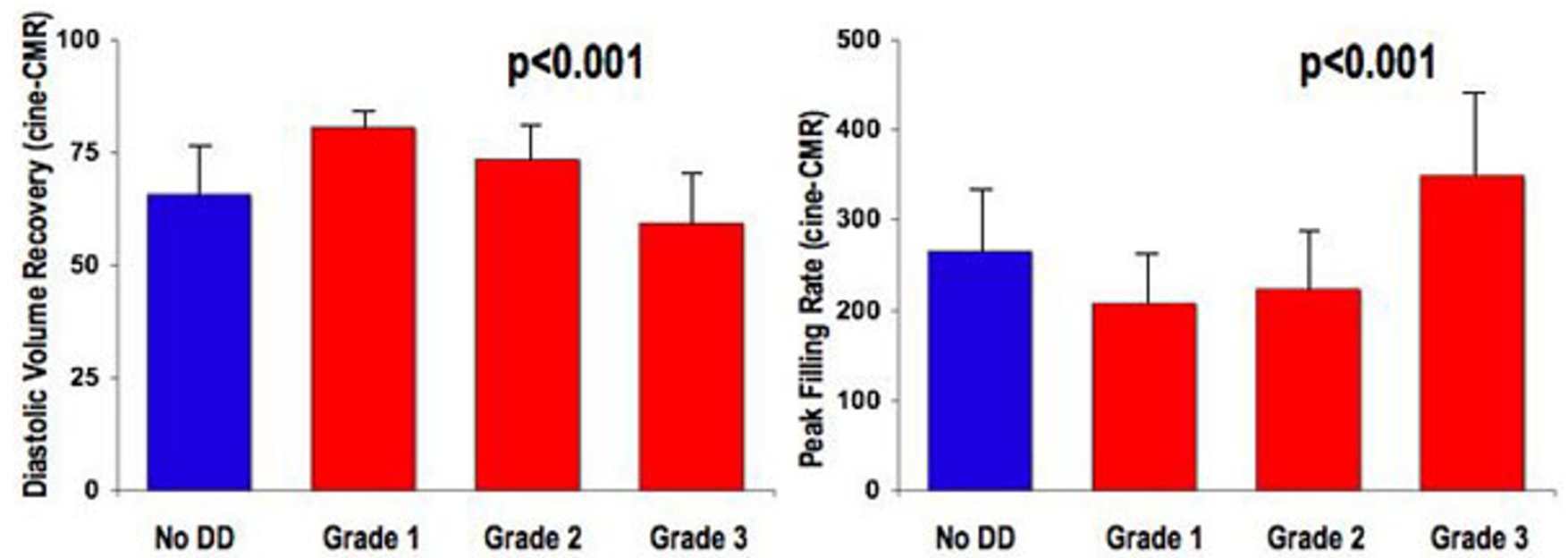

\section{Diastolic Function (Echocardiography)}

Figure I

LV Diastolic Function (Echocardiography).

\section{Conclusion}

DD changes in LV filling can be detected using automated segmentation of routine cine-CMR without any additional data acquisition. Cine-CMR diastolic filling time and peak filling rate identify presence and stratify severity of echo-evidenced DD.

Publish with Biomed Central and every scientist can read your work free of charge

"BioMed Central will be the most significant development for disseminating the results of biomedical research in our lifetime."

Sir Paul Nurse, Cancer Research UK

Your research papers will be:

- available free of charge to the entire biomedical community

- peer reviewed and published immediately upon acceptance

- cited in PubMed and archived on PubMed Central

- yours - you keep the copyright
BioMedcentral 